\title{
The budget impact of oral nutritional supplements for disease related malnutrition in elderly in the community setting
}

\author{
Karen Freijer ${ }^{1}{ }^{*}$, Mark J. C. Nuijten ${ }^{2}$ and Jos M. G. A. Schols ${ }^{3}$ \\ ${ }^{1}$ CAPHRI - School for Public Health and Primary Care, Maastricht University, Maastricht, Netherlands \\ ${ }^{2}$ Ars Accessus Medica, Jisp, Netherlands \\ ${ }^{3}$ CAPHRI - School for Public Health and Primary Care, Department of General Practice and Department of Health Services Research, Maastricht University, \\ Maastricht, Netherlands
}

\section{Edited by:}

Javed S. Shaikh, Cardiff Research

Consortium: A CAPITA Group PIC

Company, India

Reviewed by:

Sirajudheen Anwar, University of Messina, Italy

Domenico Criscuolo, Genovax, Italy

Michael Hans Thiede, Health

Economics and Policy, Germany

\section{*Correspondence:}

Karen Freijer, CAPHRI School for Public Health and Primary Care, PhD

student, p/a P.O. Box 445, 2700 AK

Zoetermeer, Netherlands.

e-mail:k.freyer@

maastrichtuniversity.nl
A health economic analysis was performed to assess the economic impact on the national health care budget of using oral nutritional supplements (ONS), being a food for special medical purposes also known as medical nutrition, for the treatment of disease related malnutrition (DRM) in the community in the Netherlands. An economic model was developed to calculate the budget impact of using ONS in community dwelling elderly ( $>5$ years) with DRM in the Netherlands. The model reflects the costs of DRM and the cost reductions resulting from improvement in DRM due to treatment with ONS. Using ONS for the treatment of DRM in community dwelling elderly, leads to a total annual cost savings of $€ 13$ million (18.9\% savings), when all eligible patients are treated. The additional costs of ONS ( $€ 57$ million) are more than balanced by a reduction of other health care costs, e.g., re-/hospitalization ( $€ 70$ million). Sensitivity analyses were performed on all parameters, including duration of treatment with ONS and the prevalence of DRM. This budget impact analysis shows that the use of ONS for treatment of DRM in elderly patients in the community may lead to cost savings in the Netherlands.

Keywords: disease related malnutrition, medical nutrition, oral nutritional supplements, economic impact, budget impact, costs

\section{INTRODUCTION}

Malnutrition is a prevalent problem, which is known for many years and is defined as a state of nutrition in which a deficiency, excess (or imbalance) of energy, protein, and other nutrients causes measurable adverse effects on tissue/body form (body shape, size, and composition) and function, and clinical outcome (Stratton et al., 2003). Malnutrition thus includes both over-nutrition (overweight and obesity) and under-nutrition (insufficient nutrition). For the purposes of this article the term malnutrition is used only for under-nutrition in health care, which is caused by changes of the body metabolism due to acute or chronic diseases and/or treatment interventions, which increases the daily nutritional needs, also known as disease related malnutrition (DRM). Due to lack of adequate nutrition because of this increased nutritional need, an individual may move from a good nutritional status to frank DRM in a matter of weeks, months, or years. The key factor in the development of DRM is a nutritional intake that is insufficient to meet the increased nutritional requirements. DRM adversely impacts on every organ system in the body with potentially serious consequences on a physical and psycho-social level that in turn contribute to increased morbidity and mortality (Elia and Russell, 2009).

Abbreviations: DRM, disease related malnutrition; FSMP, food for special medical purposes; iMTA Institute for Medical Technology Assessment B. V. (iMTA) of the Erasmus University Rotterdam; ONS, oral nutritional supplements
As a consequence, treatment should be focused not only on the underlying disease but also on the nutritional status.

Disease related malnutrition is highly prevalent in Europe, as about 20 million patients are affected by DRM, costing EU governments up to $€ 120$ billion annually (Ljungqvist and de Man, 2009; Ljungqvist et al., 2010). DRM affects many people across all healthcare settings, from older people living in the community to patients in the hospital with specific conditions. A comparison of the results of the measurement of DRM in the Netherlands, Austria, Switzerland, New Zealand, and Germany show that about $25 \%$ of hospitalized patients and patients in care homes are malnourished (Halfens et al., 2011). European studies regarding the community dwelling elderly, report a prevalence of DRM ranging from $19 \%$ in Russia up to $84 \%$ in Ireland (Stratton et al., 2003; Gurina et al., 2011).

In the Netherlands about $50 \%$ of the patients in all healthcare settings are at risk of DRM and $25 \%$ are actually malnourished (Halfens et al., 2009). Comparing prevalence rates in different countries and settings thus reveals that DRM in general is common, but that there is considerable fluctuation due to no universally accepted definition of malnutrition and screening tools for DRM.

As mentioned, DRM is common across a variety of patient and age groups, but older people are particularly at risk; a large-scale survey showed that the risk is $40 \%$ greater in people aged over 65 years, than in people under 65 years (Russell and Elia, 2009). 
With an aging population DRM continues to be a major public health concern.

The consequences of DRM, if left untreated, are serious: increased complication rates, morbidity, mortality, hospital readmissions, and length of hospital stay (Elia et al., 2005; Sorensen et al., 2008). These consequences result in an increased use of healthcare resources (extra physicians' visits, extended length of stay in hospitals, extra costs in care homes, etc., Martyn et al., 1998). In 2007 a cost of illness study was performed in the Netherlands by the Institute for Medical Technology Assessment B. V. (iMTA) of the Erasmus University Rotterdam. This study reports that the additional costs of DRM in the Netherlands are $€ 1.7$ billion in 2006, which equals $2.8 \%$ of the total Dutch national health expenditures at that time (see Costs of DRM).

Patients with DRM are often not able to meet the increased nutritional requirements with their daily food due to a number of different reasons related to disease and disability, impacting on food intake, losses of nutrients, and/or increased requirements. Although in some cases improvement of the quality or quantity of food supplied can ameliorate the problem, in many cases the person concerned is simply unable or unwilling to consume sufficient normal food to meet their requirements to manage the DRM. In this case, it is vital to consider other options to improve nutritional intake, such as enteral nutritional support. The term enteral nutrition, also known as medical nutrition, comprises all forms of nutritional support that imply the use "dietary foods for special medical purposes (FSMP)" as defined by the European Commission Directive 1999/21/EC independent of the route of application. It includes oral nutritional supplements (ONS) as well as tube feeding via nasogastric, nasoenteral, or percutaneous tubes (Lochs et al., 2006). Meta-analyses on treatment of DRM with medical nutrition show a reduction in mortality and complications (e.g., sepsis, wound care, and pneumonia), improvement of wound healing, and an increase of Quality of Life (Elia et al., 2005; Stratton et al., 2005; Sneller beter, 2008). Stratton and Elia (2007) concluded that enteral nutritional support can be an important part of the management of any patient.

The published literature (meta-analyses and systematic reviews) provides evidence that ONS, being a food FSMP, are an effective treatment for patients with DRM:

- Mortality rates are significantly lower (odds ratio of $0.61 ; 95 \%$ CI 0.48-0.78; Stratton et al., 2003). Meta-analyses consistently show a reduction in mortality, e.g., a 24\% reduction (Stratton et al., 2003), particularly in undernourished older people (Milne et al., 2005, 2006, 2009).

- Complication rates, including infections, are significantly reduced (odds ratio of 0.31 ; 95\% CI 0.17-0.56; Stratton et al., 2003; Stratton and Elia, 2007). Another systematic review showed that medical nutrition can significantly reduce the risk (25\% risk reduction) of developing pressure ulcers (Stratton et al., 2005).

- ONS have been demonstrated to be more effective than dietary advice and snacks (Stratton et al., 2006; Stratton and Elia, 2007).

- Potential cost savings as a result of reduced healthcare use can be realized in both the hospital and the community setting (NICE, 2006). A previous Dutch health economic analysis by our group showed that the use of ONS for treating patients in the hospital setting would lead to an annual cost saving of $€ 40.4$ million per year in the Netherlands (Freijer and Nuijten, 2010).

In summary, DRM is common and may be costly, if left untreated. Therefore the objective of this study is to assess the economic benefit for the society in the Netherlands when community dwelling elderly ( $>65$ years) patients with DRM are treated with ONS.

\section{MATERIALS AND METHODS HEALTH ECONOMIC MODELING - MODEL DESIGN}

A health economic model was constructed using decision analytical techniques (Weinstein et al., 1980). The model calculates the budget impact of using ONS in patients who are eligible (see Study Population: Type of Patients, Type of Intervention, and Comparator, The Total Number of Patients, and Prevalence of Disease Related Malnutrition) for ONS due to DRM. The model allows the assessment of the cost savings resulting from improvement in DRM due to treatment with ONS. Clinical probabilities and resource utilization were based on clinical trials and published literature (see Re-/Hospitalization); cost data were derived from official price tariffs.

Figure 1 shows the structure of the model for treatment with ONS. The first branch point in a tree is called a decision node because it corresponds to a choice of treatment - ONS or "no ONS" - in patients eligible for ONS due to DRM. A decision node is represented as a small square $(\square)$. Subsequent to the decision node, the structure of the decision tree is shown, which is identical for both treatment options. The other branch points indicate probabilities. DRM status may improve (reduction of malnutrition), or may deteriorate or remain similar (no reduction of malnutrition).

Data sources used included published literature, clinical trials, official Dutch price/tariff lists, and national population statistics. To be able to test the robustness of the outcomes of the model to the variance in the input values, a sensitivity analysis was performed. A sensitivity analysis is a technique for systematically changing variables in a model to determine the effects of such changes (Saltelli et al., 2008). Our univariate sensitivity analyses (a single variable and its attributes of the applicable major entity that is being analyzed in the study) were based on the modification of the basic clinical and economic assumptions in the model. This procedure entails changing one of the model parameters through a range of plausible values and assessing the effect on the overall outcome of the analysis.

\section{STUDY POPULATION: TYPE OF PATIENTS, TYPE OF INTERVENTION, AND COMPARATOR}

The study population is based on a comparison of the use of ONS versus "no use" of ONS due to DRM in elderly patients of 65 years and over ( $>65$ years) in the community setting. ONS is the intervention and "no use" of ONS is the comparator, meaning that this group of patients with DRM is getting the standard care (e.g., their normal daily food as usual without any special nutritional intervention like ONS). This study population is the most studied and common in clinical trials regarding ONS. To be able to calculate the budget impact of the use of ONS, an incremental costing 


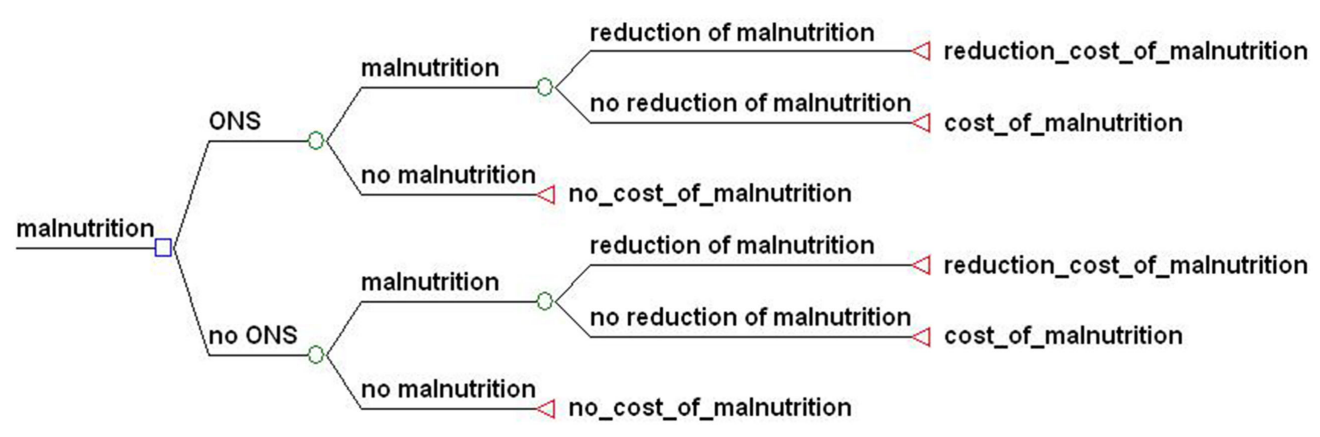

FIGURE 1 | Model to calculate the budget impact of the use of ONS; a linear decision Tree.

approach was used (see Cost Assessment). The incremental cost difference was based on the costs associated with the cost of ONS and the cost of illness of DRM. All health care costs other than use of ONS and costs of DRM are not included in the model.

The rational for selecting elderly patients is that aging will have an increasing impact on the Dutch healthcare budget. Maintaining an adequate functional status in older people is considered a high priority by the World Health Organization to help prevent disability and institutionalization (WHO, 2002). Institutionalization generally means high health care costs, especially in hospitals, which was also shown by the cost of illness analysis for DRM in the Netherlands (see Costs of DRM). Preventing hospitalization or decreasing the duration of hospitalization will therefore most probably lead to cost savings. The cost savings due to a reduction of hospital length of stay by treating patients with ONS in the Netherlands has recently been published (Freijer and Nuijten, 2010).

The focus of this analysis is on the use of ONS in the community setting. Within the national health care system in the Netherlands, the costs of treatments in the community considerably affect the total health care budget. In 2005, about $6 \%$ of the population older than 30 years received publicly financed nursing and care, two thirds received some form of home care and one third lived in a home. The sector nursing and residential care spent nearly $€$ 10 billion of the total public spending in that year, which is $\sim 2 \%$ of gross domestic product in the Netherlands. Spending on public nursing care between 2005 and 2030 is expected to increase by $3.4 \%$ per annum. This is faster than the growth in the number of users $(1.2 \%)$ and a result of rising health care costs and increasing health care needs (Woittiez et al., 2009). Therefore interventions used to manage DRM in the community setting in the Netherlands, may have a major impact on the national health care budget. Patients living at home, who may, or may not be assisted by home care and patients living in residential homes, are considered community dwelling patients (Schols et al., 2004). Dutch home care services deliver care and nursing to patients living at home. This involves general and special nursing, household care and personal care. Residential homes offers assisted living (a save living environment) to older people who are still able to do a considerable part of their daily activities themselves. The perspective of this study is that of the compartment of patients living at home with assistance of home care ("thuiszorg" in Dutch) and patients living in residential homes ("verzorgingshuis" in Dutch) being the community setting.

\section{COST ASSESSMENT}

An incremental costing approach was used: all drug utilization (and other health care utilization), being similar between the two treatment arms, is not included in the model. The incremental cost difference was based on the costs associated with the cost of ONS and the cost of illness of DRM. The model is based on the assumption that the use of ONS only has an impact on re-/hospitalization due to DRM.

The perspective of the study was a limited societal perspective, because indirect costs due to productivity loss were not included, as the study population concerns elderly people, most likely to be retired. Discounting of costs and effectiveness measures was not performed, because the time horizon of the model did not exceed 1 year.

\section{DATA}

\section{The Total Number of Patients}

The Dutch Central Buro for Statistics (CBS) reports that the total number of elderly patients ( $>65$ years) in home care in the Netherlands was 499,700 in 2004 (CBS, 2006). As no data were available for 2009 , the increase from 119,000 in five previous years was extrapolated to the subsequent 5 years giving a figure of 620,000 in 2009 using CBS (2006) data. There are 100,223 persons living in residential homes in the Netherlands (Actiz, 2009). As these data do not indicate the proportion of patients older than 65 years, we made the assumption that $100 \%$ is 65 years or older. The analysis is therefore based on a total number of 720,223 patients in 2009 .

\section{Prevalence of Disease Related Malnutrition}

In the Netherlands the department of Health Care and Nursing Science of the University of Maastricht is performing an annual national independent measurement of health care problems. Since 2004 this annual Dutch National Prevalence Measurement of Care Problems (LPZ) includes also an audit on DRM. The report of 2009 shows that one out of two patients in the Dutch health care system is at risk of DRM and 25\% is malnourished. In home care and care homes the prevalence of DRM is somewhat lower but the prevalence of DRM is still $20 \%$ with a mean age of the population of 77 years (Halfens et al., 2009). The base case analysis is based on data from this Dutch report, which provides a prevalence of $20 \%$ of DRM in elderly (>65 years) living in the community setting. 


\section{Re-/hospitalization}

A number of studies have been done in the community setting, but only a few have incorporated end-points which are amenable to economic modeling. Nevertheless, three studies in the community have shown that ONS result in a reduction in re-/hospitalization (Gariballa et al., 2006; Norman et al., 2008a; Chapman et al., 2009). Re-/hospitalization is a key driver of costs and is one of the consequences of DRM (Martyn et al., 1998; Elia et al., 2005; Sorensen et al., 2008) when left untreated. To be able to calculate the budget impact of ONS for malnutrition in the community setting, we used the re-/hospitalization data as indication for the impact of ONS on DRM due to lack of other amenable data. For each study we calculated the probability of re/hospitalization (Table 1) which was then used as a measure for the reduction of DRM; for our economic analysis, a probability of 0.72 means that DRM is reduced by $27 \%$.

The study by Gariballa tested whether ONS for older patients ( $>65$ years) during acute illness leads to a clinical benefit. This study provided a reduction of re-/hospitalization from 40 to $29 \%$ over a period of 6 months (Gariballa et al., 2006). In another study by Chapman, ONS was tested in community dwelling undernourished elderly alone or in combination with a hormonal supplement. Fewer patients needed hospitalization in the group, which received only the ONS (38.5\%) versus the group which received the no (=standard) treatment (69\%; Chapman et al., 2009). Norman studied the effect of ONS (intervention group) versus no ONS (control group) in malnourished patients after hospital discharge for 3 months. Non-elective readmissions were higher in the control group than in the intervention group (48 and 26\% respectively; Norman et al., 2008a).

For clinical outcomes, the general rule may be to assume that data are not country-specific (Nuijten, 1998). Re-/hospitalization is considered a clinical outcome. Therefore the international data on re-/hospitalization were used in this analysis for a Dutch health economic evaluation of ONS in elderly patients ( $>65$ years) in the community setting.

The base case analysis was based on a rather conservative reduction of DRM of $25 \%$ based on the most conservative probability of reduction in re-/hospitalization shown in the described international studies (Table 1).

\section{Recommended amount of intake, duration, and type of ONS}

The typical prescription for ONS is two bottles $(2 \mathrm{ml} \times 200 \mathrm{ml})$ per day per patient. The studied duration of time using ONS varies from 6 weeks (Gariballa et al., 2006) to 1 year (Chapman et al., 2009). In the study by Norman the duration of ONS was

Table 1 | Results of international studies and meta-analysis on probability of re-/hospitalization of ONS.

\begin{tabular}{lllll}
\hline Re- hospitalization & $\begin{array}{l}\text { With } \\
\text { ONS (\%) }\end{array}$ & $\begin{array}{l}\text { Without } \\
\text { ONS (\%) }\end{array}$ & $\begin{array}{l}\text { Difference } \\
\text { (\%) }\end{array}$ & Probability \\
\hline Gariballa et al. (2006) & 29 & 40 & 11 & 0.72 \\
Chapman et al. (2009) & 38 & 69 & 31 & 0.55 \\
Norman et al. (2008a) & 26 & 48 & 22 & 0.54
\end{tabular}

3 months (Norman et al., 2008a). International recommendations for patients who are identified as malnourished on screening, state that monitoring should be in place monthly to every $2-3$ months with a maximum of monitoring for three to 6 months by healthcare professionals with the relevant skills and training ${ }^{1,2}$. The base case analysis was based on the most realistic and conservative period of 3 months.

The Dutch Guidelines for the treatment of DRM describe the nutritional need for patients with DRM, including the use of ONS (Stuurgroep Ondervoeding, 2011). The type of this nutrition intervention depends on several facts, like the nutritional intake with the daily food, which differs per patient. For our analysis we used the price of the most used ONS product (a "standard" ONS), containing energy $(1.5 \mathrm{kcal} / \mathrm{ml})$ and all the basic nutrients like protein carbohydrates, fat, fibers, and vitamins and minerals.

\section{Costs of DRM}

In 2007 a rough estimate was made for the disease related costs of malnutrition in the Netherlands by a university-based scientific institute that is distinguished by independent research in medical technology assessment, including health economics and health outcomes research and dedicated to support the use of costeffectiveness information in healthcare decision making (Institute for Medical Technology Assessment B.V. - iMTA, Erasmus University, Rotterdam, The Netherlands). The total additional costs of DRM in the total care sector were estimated at $€ 1.7$ billion for 2006 which equals $2.8 \%$ of the total Dutch national health expenditure and $5.8 \%$ of the total costs of the healthcare sectors analyzed in the report (hospital-, nursing home-, residential home-, and home care setting) at that time (Van der Heijden et al., 2009). The total costs of DRM were analyzed separately according to gender (men and women), age (" $18<$ age $<60$ " and "age $>60$ "), healthcare sector (hospital-, nursing home-, care home-, and home care setting), and disease. To be able to take into account the effects of aging, because especially old people use a lot of care, analyses were made for an age group of patients older than 18 and younger than 60 years of age and for the group of 60 years and older. About $50 \%$ of the total expenditure on DRM was attributable to the hospital setting ( $€ 830$ million). The proportions for the nursing home- ( $€ 352$ million), residential home- ( $€ 305$ million), and home care setting ( $€ 196$ million) accounted for 21 , 18 , and $12 \%$ respectively. The calculations were based on the total costs per illness category, national prevalence data on DRM and a weighting factor for the extra costs of care for patients with DRM versus patients with no DRM. The total costs of care per illness category were based on the data of the Dutch National Institute for Public Health and the Environment (RIVM) from 2003, which were indexed to 2006 (Slobbe et al., 2006). The national prevalence data on DRM were taken from the LPZ of that year (Meijers et al., 2006) and the weighting factor was based on a Dutch study which showed that the length of stay for patients with DRM was longer (30\%) than for patients without DRM (Kruizenga et al., 2005). For home care, residential-, and nursing home care, international

\footnotetext{
${ }^{1}$ www.bapen.org.uk

2 www.NICE.org.uk
} 
studies have shown a significantly increased use of healthcare resources and costs by patients identified as malnourished or at risk of malnutrition compared with non-malnourished patients (Stratton et al., 2003; Müller et al., 2007; Norman et al., 2008b; Banks et al., 2010; Cawood et al., 2010a). As concrete figures of the increase use of healthcare resources in these settings in the Netherlands are lacking, the same weight factor of 1.3 for these non-hospital sectors was used.

Moreover, this weighting factor of 1.3 was comparable with those used for the estimations of the costs of DRM in the United Kingdom and in Germany (1.3 and 1.4 respectively; Elia et al., 2005; Pirlich et al., 2006). For our current analysis, we used this iMTA report and indexed the costs of DRM per illness category to 2009, using the inflation index rate from CBS, Statistics Netherlands. We only did this indexing for the group of patients aged 60 years of age and older (elderly) in the settings residentialand home care, as these settings are community settings in the Netherlands (Table 2).

\section{Costs of Treatment}

The price of a standard bottle ONS is $€ 2.20$, which corresponds with the list price in 2009 as registered in the Dutch market. The costs for a hospital are lower due to discounts. The costs for a patient at the pharmacy are higher due to a mark-up for the pharmacist and VAT. Therefore the most realistic price for a bottle would be $€ 2.37$, including VAT, which is used in the analysis.

Table 2 | Costs of DRM in elderly ( $>60$ years) per illness category in community in the Netherlands in 2009 (million Euros)*.

\begin{tabular}{llll}
\hline Illness category & Residential home & Home care & Total \\
\hline Infectious diseases & 720.000 & 1.160 .000 & 1.880 .000 \\
Cancer & 1.816 .765 & 16.083 .713 & 17.900 .478 \\
Endocrinology & 971.757 & 3.215 .000 & 4.186 .757 \\
Diabetes & 1.228 .387 & 3.215 .000 & 4.443 .387 \\
Hematology & 230.000 & 1.520 .000 & 1.750 .000 \\
Psychiatry & 83.775 .896 & 11.047 .385 & 94.823 .280 \\
Neurology & 997.523 & 4.782 .222 & 5.779 .745 \\
Dementia & 1.394 .273 & 10.294 .199 & 11.688 .472 \\
Spinal cord injury & 1.193 .333 & 7.173 .333 & 8.366 .667 \\
Eye/ear & 0 & 0 & 0 \\
Cardiovascular & 10.206 .524 & 15.590 .556 & 25.797 .080 \\
CVA, hemiparesis & 13.288 .667 & 16.026 .517 & 29.315 .184 \\
Respiratory & 3.709 .924 & 8.221 .544 & 11.931 .468 \\
Gastro-intestinal & 913.889 & 7.731 .331 & 8.645 .220 \\
Urogenital & 904.896 & 0 & 904.896 \\
Dermatology & 436.739 & 2.446 .434 & 2.883 .173 \\
Musculoskeletal & 2.976 .678 & 32.377 .870 & 35.354 .549 \\
Congenital & 0 & 0 & 0 \\
Traumata - intoxications & 4.849 .538 & 5.143 .498 & 9.993 .036 \\
Hip replacement & 0 & 0 & 0 \\
Total & 109.730 .125 & 146.028 .603 & 275.643 .390 \\
& & & \\
\hline & & &
\end{tabular}

* Based on cost of care per illness of the Dutch National Institute for Public Health and the Environment (RIVM; Slobbe et al., 2006) indexed to 2009.

\section{RESULTS}

\section{BASE CASE ANALYSIS}

The base case analysis is based on the following values:

- Total number of patients: A total of 720,223 patients were used for the base case analysis, based on national data (see The Total Number of Patients; CBS, 2006; Actiz, 2009). The sensitivity analysis is based on a range varying between plus and minus $10 \%$ of the total number of patients.

- Proportion of DRM: The base case analysis (20\%) is based on Dutch data regarding prevalence of DRM in the community setting in the Netherlands (Halfens et al., 2009). The sensitivity analysis is based on a range varying the base case value by plus and minus $10 \%$ and plus and minus $20 \%$. We tested two ranges in order to assess the level of sensitivity of the outcomes of the model to this parameter as this parameter is key driver of the model.

- Duration and amount of intake of treatment with ONS: The base case analysis is based on a mean duration of treatment of 12 weeks with $2 \mathrm{ml} \times 200 \mathrm{ml}$ per day (see Recommended Amount of Intake, Duration, and Type of ONS). A sensitivity analysis is performed varying the duration from 2 to 4 months.

- Reduction of DRM: the base case analysis was based on a rather conservative reduction of DRM of $25 \%$ based on the most conservative probability of reduction in re-/hospitalization shown in the described international studies (see Re-/Hospitalization).

The results of the base case analysis are shown in Table 3. This analysis shows that the use of ONS for elderly with DRM in the community setting does not lead to additional costs. In fact, the use of ONS reduces the costs from $€ 275.643$ to $€ 262.657$ million which corresponds with a total national cost saving of $€ 12.986$ million (4.7\% savings). The additional costs of ONS ( $€ 57.335$ million) are more than balanced by a reduction of the total costs of DRM due to a reduction of re-/hospitalization. Therefore, the use of ONS would lead to a positive annual budget impact of nearly $€ 13$ million when all eligible patients are treated, based on the population of 720,223 patients living in the community setting in the Netherlands in 2009.

\section{SENSITIVITY ANALYSIS}

The results of the sensitivity analyses are presented in Table 4 . We tested two ranges in the sensitivity analysis in order to assess the sensitivity of the outcomes of the model to the key parameters in the model. These results show that the use of ONS remains cost saving compared with "no use" of ONS in nearly all sensitivity

Table 3 | Results of the base case analysis: budget impact of ONS (without and with ONS) in elderly with DRM in the community in the Netherlands in 2009 (million Euros).

\begin{tabular}{lllr}
\hline & Without ONS & With ONS & Savings \\
\hline Costs of DRM & $€ 275.643$ & $€ 205.322$ & $€ 70.321$ \\
Costs of ONS & $€ 0$ & $€ 57.335$ & $-€ 57.335$ \\
Budget impact & $€ 275.643$ & $€ 262.657$ & $€ 12.986$
\end{tabular}


Table 4 | Results of the base case* and the sensitivity analyses** (million Euros).

\begin{tabular}{lllll}
\hline Analysis & Range*** & $\begin{array}{l}\text { Without } \\
\text { ONS }\end{array}$ & $\begin{array}{l}\text { With } \\
\text { ONS }\end{array}$ & Savings \\
\hline Base case & & $€ 276$ & $€ 263$ & $€ 13$ \\
Prevalence malnutrition & $-10 \%$ & $€ 276$ & $€ 257$ & $€ 18$ \\
& $+10 \%$ & $€ 276$ & $€ 268$ & $€ 7$ \\
& $-20 \%$ & $€ 276$ & $€ 251$ & $€ 24$ \\
& $+20 \%$ & $€ 276$ & $€ 274$ & $€ 1$ \\
Total number of patients & $-10 \%$ & $€ 276$ & $€ 257$ & $€ 18$ \\
& $+10 \%$ & $€ 276$ & $€ 268$ & $€ 7$ \\
Duration of treatment ONS & -1 month & $€ 276$ & $€ 244$ & $€ 32$ \\
& +1 month & $€ 276$ & $€ 282$ & $-€ 6$ \\
\hline
\end{tabular}

*The overall outcome of the budget impact analysis following the calculation model for using ONS or not using ONS by elderly patients in the community.

${ }^{*}$ Checking the robustness (sensitivity) of the base case by changing one of the model parameters through a range of plausible values.

***The values used in the base case are changed by a range of plausible values.

analyses. The budget impact is most sensitive to the duration of treatment with ONS; the break even for the duration of treatment is 3.7 months.

\section{DISCUSSION AND CONCLUSION}

An analysis was performed to assess the economic impact of the use of ONS in community dwelling elderly patients ( $>65$ years) with DRM, on the national health care budget in the Netherlands. The rational for performing this budget impact analysis for the cohort of elderly patients in the community is that the aging society in the Netherlands in the future will have a high impact on the healthcare budget. Therefore interventions used to manage DRM in the community setting in the Netherlands, may have a major favorable impact on the national health care budget, as the proportion of elderly will increase. Each year the Dutch Ministry of Health has to decide which interventions will be reimbursed and an budget impact calculation can provide valuable information for the decision making process. This budget impact analysis shows that using ONS for the treatment of DRM in community dwelling elderly leads to cost savings: additional costs for ONS are offset by substantial cost savings and therefore support the existing clinical guidelines also from an economic point of view. In the UK, the British Association for Parenteral and Enteral Nutrition (BAPEN) has used a similar approach to inform their National Institute for Health and Clinical Excellence (NICE) to support the guideline development and contribute to the evidence base, as economic evaluations are included in their guidance in order to recommend those treatments that represent value for money. Their systematic analysis of the costs of DRM in the UK and use of ONS in hospital and community settings showed also some insights into the economic burden of malnutrition and the value of ONS in one healthcare system (Russell, 2007).

Recently other economic studies in the field of DRM have been performed for the UK by Guest et al. (2011) and Cawood et al. (2010b) and for Germany by Norman et al. (2011). The study of Guest et al. can be considered a cost of illness study as this study gives a good overview of the current way malnourished patients are treated in the community including the economic impact, although the nutritional intervention was often inappropriate (vitamin and mineral supplements). Guest et al. also show that only $23 \%$ of the malnourished patients are actually treated with a nutritional intervention. The study by Cawood et al. has yet only been published as an abstract, but the described methods seem similar to our analysis. A big difference in both budget impact analyses is the inclusion of the cost of patient monitoring, which is one of the limitations of our study. The study by Norman et al. is a cost utility analysis of ONS, in which the cost-effectiveness of the improvement of quality of life has been calculated in terms of quality adjusted life years (QALY). Both studies provide important information on the economics of DRM, but the UK study does not include the impact of ONS, and the German study is limited to the patient-based level without extrapolation to the economic impact at a population level. As a consequence the results of these two studies are not comparable with the results of our own economic analysis. In addition, the two studies were performed outside the Netherlands, where different treatment patterns and financing systems may lead to different costs.

One of the limitations of our study is that we did not include all costs due to lack of data, e.g., the cost of patient monitoring (assessment and follow up) for DRM.

Also due to lack of data on patients living at home without assistance of home care, the perspective of this study is that of the compartment of patients living at home with assistance of home care. This may also be a limitation of this study.

The used duration of treatment with ONS may be another limitation. Patients of 65 years and older with a range of chronic diseases could be in need of ONS for a longer period of time than 3 months to recover from DRM. The treatment with ONS could then lead to a cost-increase. The sensitivity analysis on the duration of treatment though, showed that the outcome of the model is rather robust to changes in treatment duration. Finally we had to use indirect clinical data for calculating the direct effect of ONS on DRM. As only data of the effect of ONS in the community exist on re-/hospitalization, which is one of the consequences of DRM (Martyn et al., 1998; Elia et al., 2005; Sorensen et al., 2008), we used re-/hospitalization as the efficacy measure of ONS on DRM. The probability value on re-/hospitalization we used in this analysis (0.75) has been confirmed by a recent meta-analysis on hospital re-/admission. This systematic review and meta-analysis by Stratton et al. examined the effect of ONS versus routine care (no ONS) on admissions/readmissions in the community setting. The three studies we used as basis for our analysis were part of the total amount of six studies used in this meta-analysis. ONS significantly reduced the proportion of patients admitted or readmitted to hospital from 33 to $24 \%$ with a probability of 0.73 . When including only trials in the elderly (mean age $\geq 65$ years), the result remained significant [OR 0.63 (95\% CI 0.45-0.88), $p=0.007$; Stratton et al., 2011]. Implicitly we also assumed that there is no difference in mortality, complications and Quality of Life between the use of ONS versus "no use" of ONS in malnourished elderly patients living in the 
community. This is a conservative assumption toward the use of ONS, because studies in elderly have shown a reduction in mortality, complications and an improvement in Quality of Life (Milne et al., 2005, 2006; Stratton et al., 2005; Chapman et al., 2009) which are also consequences of DRM. But because of the fact that these outcomes were not specific enough, we did not use these data in our model. So the real economic benefits for the use of ONS may be in fact higher than was calculated with the current data set.

Despite the limitations, we have shown that the use of ONS has a positive impact on the national budget, because:

1) Total costs for treatment with ONS are not higher than a treatment strategy without ONS: the additional costs for ONS are more than balanced by a reduction of the health care costs due to a reduction of the costs of DRM.

2) The analysis is based on similar clinical properties for both treatment strategies with regards to mortality and complications. However, the use of ONS is associated with a higher effectiveness, as this treatment leads to a reduction of DRM only.

\section{REFERENCES}

Actiz. (2009). Cijfers. Available at: http:// www.actiz.nl/

Banks, M. D., Graves, N., Bauer, J. D., and Ash, S. (2010). The costs arising from pressure ulcers attributable to malnutrition. Clin. Nutr. 29, 180-186.

Cawood, A. L., Rust, S., Walters, E., Stratton, R. J., and Elia, M. (2010a). The impact of malnutrition on health care use in hospital outpatients. Proc. Nutr. Soc. 69, E149.

Cawood, A. L., Green, C., and Stratton, R. J. (2010b). The budget impact of using oral nutritional supplements in older community patients at high risk of malnutrition in England. Proc. Nutr. Soc. 69, E544.

Centraal Bureau voor de Statistiek (CBS). (2006). Gezondheid en zorg in cijfers. Available at: http://www. cbs.nl/ [accessed 2006].

Chapman, M., Visvanathan, R., Hammond, A. J., Morley, J. E., Field, J. B., Tai, K., Belobrajdic, D. P., Chen, R. Y., and Horowitz, M. (2009). Effect of testosterone and a nutritional supplement, alone and in combination, on hospital admissions in undernourished older men and women. Am. J. Clin. Nutr. 89, 880-889.

Elia, M., and Russell, C. (2009). Combating Malnutrition: Recommendations for Action. Report from the Group on Malnutrition, Led by BAPEN. 2009. Redditch: BAPEN.

Elia, M., Stratton, R. J., Russell, C., Green, C. J., and Pang, F. (2005). The Cost of Disease-Related Malnutrition in the UK and Economic Considerations for the use of Oral Nutritional
Supplements (ONS) in Adults. Redditch: BAPEN. Analysis of the health economic impact of medical nutrition in the Netherlands. Eur. J. Clin. Nutr. 64, 1229-1234.

Gariballa, S., Forster, S., Walters, S., Powers, H. (2006). A randomized double-blind placebo-controlled trial of nutritional supplementation during acute illness. Am. J. Med. 119, 693-699.

Guest, J. F., Panca, M., Baeyens, J. P., de Man, F., Ljungqvist, O., Pichard, C., Wait, S., and Wilson, L. (2011). Health economic impact of managing patients following a community-based diagnosis of malnutrition in het UK. Clin. Nutr. 30, 422-429.

Gurina, N. A., Frolova, E. V., and Degryse, J. M. (2011). A roadmap of aging in Russia: the prevalence of frailty in community-dwelling older adults in the St. Petersburg district the "Crystal" study. J. Am. Geriatr.

Halfens, R. J. G., Meijers, J. M. M., Neyens, J. C. L., and Schols, J. M. G. A. (2009). "Ondervoeding," in Rapportage resultaten. Landelijke prevalentiemeting zorgproblemen 2009 (Maastricht: Department of Health Care and Nursing Sciences, Onderzoeksinstituut Caphri, Universiteit Maastricht), 71-89.

Halfens, R. J. G., Schols, J. M. G. A., Bartholomeyczik, S., Reuter, S., Saxer, S., Lohrmann, C., Schönherr, S., Weststrate, J., and Nie van, N. C. (2011). International Prevalence Measurement of Care Problems
Freijer, K., and Nuijten, M. J. C. (2010). Soc. 59, 980-988.

Sensitivity analyses were performed and resulted in the fact that the use of ONS in nearly all parameters remains cost saving compared to "no use" of ONS. The budget impact is most sensitive to the duration of treatment with ONS. Treating patients for 4 months with $2 \mathrm{ml} \times 200 \mathrm{ml}$ per day, the costs savings are lost. The break even for using the ONS is 3.7 months, meaning that at that point the costs and the savings are equal.

In conclusion, this budget impact analysis for the use of ONS in elderly patients ( $>65$ years) with DRM living in the community setting in the Netherlands showed that the use of ONS in this group of patients may lead to a positive impact on the national health care budget in the Netherlands.

\section{ACKNOWLEDGMENTS}

Each author has participated in the work of this publication. Karen Freijer and Mark J. C. Nuijten designed the study, developed the health economic calculation models, performed the data and statistical analyses and interpreted the data. KF drafted the manuscript in her job as a Ph.D. student. Jos M. G. A. Schols helped to draft the manuscript and approved the final version for submission.

(LPZ): 2009-2010 at a Glance. Maastricht: Datawyse.

Kruizenga, H. M., van Tulder, M. W., Seidell, J. C., Thijs, A., Ader, H. J., and van de Bokhorst-van der Schueren, M. A. E. (2005). Effectiveness and cost-effectiveness of early screening and treatment of malnourished patients. Am. J. Clin. Nutr. 82, 1082-1089.

Ljungqvist, O., and de Man, F. (2009). Under nutrition - a major health problem in Europe. Nutr. Hosp. 24, 68-370.

Ljungqvist, O., van Gossum, A., Sanz, M., and de Man, F. (2010). The European fight against malnutrition. Clin. Nutr. 29, 149-150.

Lochs, H., Allison, S. P., Meier, R., Pirlich, M., Kondrup, J., Schneider, S., van den Berghe, G., and Pichard, C. (2006). Introductory to the ESPEN guidelines on enteral nutrition: terminology, definitions and general topics. Clin. Nutr. 25, 180-186.

Martyn, C. N., Winter, P. D., Coles, S. J., and Edington, J. (1998). Effect of nutritional status on use of health care resources by patients with chronic disease living in the community. Clin. Nutr. 17, 119-123.

Meijers, J. M. M., Janssen, M. A. P., Schols, J. M. G. A., van Bokhorstde van der Schueren, M. A. E., Halfens, R. J. G. (2006). "Ondervoeding," in Rapportage resultaten. Landelijke prevalentiemeting zorgproblemen 2006, (Maastricht: sectie Verplegingswetenschap, Zorgwetenschappen, Universiteit Maastricht), 79-102.

Milne, A. C., Avenell, A., Potter, J. (2006). Meta-analysis: protein and energy supplementation in older people. Ann. Intern. Med. 144, 37-48.

Milne, A. C., Potter, J., and Avenell, A. (2005). Protein and energy supplementation in elderly people at risk from malnutrition. Cochrane Database Syst. Rev. 2, CD003288.

Milne, A. C., Potter, J., Vivanti, A., and Avenell, A. (2009). Protein and energy supplementation in elderly people at risk from malnutrition. Cochrane Database Syst. Rev. 2, CD003288.

Müller, M. C., Uedelhofen, K. W., Wiedemann, U. C. H. (2007). Mangelernährungkostet 9 Milliarden Euro jährlich. Available at: http:// cepton.eu/publications/download/ Pressemitteilung-Studie-070621.pdf. German

NICE. (2006). Nutrition Support in Adults Oral Nutrition Support, Enteral Tube Feeding and Parenteral Nutrition (Clinical Guidelines 32). London: National Collaborating Centre for Acute Care, Commissioned by The National Institute for Clinical Excellence.

Norman, K., Kirchner, H., Freudenreich, M., Ockenga, J., Lochs, H., and Pirlich, M. (2008a). Three month intervention with protein and energy rich supplements improve muscle function and quality of life in malnourished patients with non-neoplastic gastrointestinal disease - a randomized controlled trial. Clin. Nutr. 27, 48-56.

Norman, K., Pichard, C., Lochs, H., and Pirlich, M. (2008b). Prognostic impact of disease-related malnutrition. Clin. Nutr. 27, 5-15. 
Norman, K., Pirlich, M., Smoliner, C., Kilbert, A., Schulzke, J. D., Ockenga, J., Lochs, H., and Reinhold, T. (2011). Cost-effectiveness of a 3-month intervention with oral nutritional supplements in disease-related malnutrition: a randomised controlled pilot study. Eur. J. Clin. Nutr. 65, 735-742.

Nuijten, M. J. (1998). The selection of data sources for use in modelling studies. Pharmacoeconomics 13, 305-316.

Pirlich, M., Schütz, T., Norman, K., Gastell, S., Lübke, H. J., Bischoff, S. C., Bolder, U., Frieling, T., Güldenzoph, H., Hahn, K., Jauch, K. W., Schindler, K., Stein, J., Volkert, D., Weimann, A., Werner, H., Wolf, C., Zürcher, G., Bauer, P., and Lochs, H. (2006). The German hospital malnutrition study. Clin. Nutr. 25, 563-572.

Russell, C., and Elia, M. (2009). Nutrition Screening Survey in the UK in 2008: Hospitals, Care Homes and Mental Health Units. Redditch: BAPEN.

Russell, C. A. (2007). The impact of malnutrition on health care costs and economic considerations for the use of oral nutritional supplements. Clin. Nutr. Suppl. 2, 25-32.

Saltelli, A., Ratto, M., Andres, T., Campolongo, F., Cariboni, J., Gatelli, D., Saisana, M., and Tarantola, S. (2008). Global Sensitivity Analysis: The Primer. Chichester: John Wiley \& Sons Ltd.

Schols, J. M. G. A., Crebolder, H. F. J. M., and van Weel, C. (2004). Nursing home and nursing home physician: the Dutch experience. J. Am. Med. Dir. Assoc. 5, 207-212.

Slobbe, L. C. J., Kommer, G. J., Smit, J. M., Groen, J., Meerding, W. J., and Polder, J. J. (2006). Kosten van ziekten in Nederland 2003, Zorg voor Euro's-1. Bilthoven: Rijksinstituut voor Volksgezondheid en Milieu.

Sneller beter. (2008). Implementatie van vroege herkenning \& behandeling van ondervoeding in de kliniek en op de polikliniek in Nederlandse ziekenhuizen. Available at: http:// www.snellerbeter.nl/ [accessed May 12, 2008].

Sorensen, J., Kondrup, J., Prokopowicz, J., Schiesser, M., Krahenbuhl, L., Meier, R., and Liberda, M. (2008). EuroOOPS: an international, multicentre study to implement nutritional risk screening and evaluate clinical outcome. Clin. Nutr. 27, 340-349.

Stratton, R., van Binsbergen, J., Volkert, D., Hebuterne, X., and Elia, M. (2011). Systematic Review and Meta-Analysis of the Effects of Oral Nutritional Supplements on Hospital Admissions. ESPEN 2011 (Abstract OPO38). Available at: https:// b-com.mci-roup.com/AbstractList/ ESPEN2011.aspx

Stratton, R. J., Bowyer, G., and Elia, M. (2006). Food snacks or liquid oral nutritional supplements as a firstline treatment for malnutrition in post-operative patients? Proc. Nutr. Soc. 65, 4A.

Stratton, R. J., Ek, A. C., Engfer, M., Moore, Z., Rigby, P., Wolfe, R., and Elia, M. (2005). Enteral nutritional support in prevention and treatment of pressure ulcers: a systematic review and meta-analysis. Ageing Res. Rev. 4, 422-450.

Stratton, R. J., and Elia, M. (2007). Who benefits from nutritional support: what is the evidence? Eur. J. Gastroenterol. Hepatol. 19, 353-358.

Stratton, R. J., Green, C. J., and Elia, M (2003). Disease-Related Malnutrition: An Evidence Based Approach to Treatment. Wallingford: CABI Publishing.

Stuurgroep Ondervoeding. (2011). Richtlijn Screening en behandeling van ondervoeding. Available at: http://www.stuurgroepondervoed ing.nl/ [accessed 2011, at fileadmin/ $\mathrm{dbc/Stuurgroep].}$

Van der Heijden, E., Schols, J. M. G. A., van Binsbergen, J. J., Evers, A. M., Kruizenga, H. M., Remijnse, T. A., Schols, A. M. W. J., and Mulder, C. J. J. (2009). Behandeling van ondervoeding noodzakelijk en (kosten)effectief onderdeel van het medisch handelen. TSG 8, 341-345.

Weinstein, M. C., Fineberg, H. V., Elstein, A. S, Frazier, H. S. Neuhauser, D., Neutra, R. R., and McNeil, B. J. (1980). Clinical Decision Analysis, Illustrated. Philadelphia: WB Saunders.

WHO. (2002). Active Ageing: A Policy Framework. Geneva: WHO.

Woittiez, I., Eggink, E., Jonker, J.-J., and Sadiraj, K. (2009). Vergrijzing, verpleging en verzorging. Ramingen, profielen en scenario's 2005-2030.
Den Haag: Sociaal en Cultureel Planbureau (SCP-publicatie 2009/17).

Conflict of Interest Statement: This study was sponsored by the Dutch Industry of Children and Dietary Nutrition (VNFKD), the Netherlands. The publication of the study results was not contingent on the sponsor's approval. $\mathrm{K}$. Freijer receives salary as an employee NAMN and is a posted $\mathrm{PhD}$ student at the University of Maastricht in the Netherlands. This University has an unrestricted agreement with the company (NAMN) to enable K. Freijer to do research. MJCN is an independent consultant in health economics and has been paid to do the economic calculations. JMGAS has no conflict of interest.

Received: 12 February 2012; accepted: 11 April 2012; published online: 04 May 2012.

Citation: Freijer $K$, Nuijten MJC and Schols JMGA (2012) The budget impact of oral nutritional supplements for disease related malnutrition in elderly in the community setting. Front. Pharmacol. 3:78. doi: 10.3389/fphar.2012.00078

This article was submitted to Frontiers in Pharmaceutical Medicine and Outcomes Research, a specialty of Frontiers in Pharmacology.

Copyright (c) 2012 Freijer, Nuijten and Schols. This is an open-access article distributed under the terms of the Creative Commons Attribution Non Commercial License, which permits noncommercial use, distribution, and reproduction in other forums, provided the original authors and source are credited. 